\title{
Research on the Project-based Instruction Design of MCU Course Training for the Non-Computer Majors
}

\author{
Ping $\mathrm{Wu}^{1, \mathrm{a}}$ \\ ${ }^{1}$ College of Information and Control Engineering, Weifang University, Weifang Shandong, China, \\ 261061 \\ awping1980@163.com
}

Keywords: Project-based instruction; Course training; Instruction design

\begin{abstract}
Aiming at the status quo and problems of the MCU course training for the non-computer majors, an innovative and practical project teaching design method is proposed. This paper introduces the reform goal of course training in detail, and gives a new project-based design plan and specific implementation steps in course training, so as to establish the "interactive, heuristic, research-based" course training mode which emphasizes "learning in doing, doing in learning and student-centered mode" under the guidance of teachers and to improve the students' autonomous learning ability and professional application skills.
\end{abstract}

\section{Introduction}

MCU course is a comprehensive applied discipline and an important required professional course for most science and engineering majors in universities. The course itself involves a wide range of knowledge and a large amount of information. For the non-computer majors students whose knowledge base of electricity and principles of microcomputer is weak, students can not very well understand the structure of MCU application system, will not use the microcontroller related design simulation software in the learning process, thus affecting the design ability to improve. It is an important means to cultivate high-quality applied talents through strengthening the theory teaching while strengthening the training of practice. Therefore, the key to practical teaching is to explore a reasonable set and effective implementation of professional training methods.

Practical teaching means using the actual case from real work projects by simulating the actual working environment, theory combined with practice in teaching process, more emphasis on student participation in learning, which can help students promote in professional skills, practical experience, working methods, teamwork and so on in the shortest possible time. The ultimate goal of training is to improve the professional quality of students, and ultimately achieve the satisfaction of both students and employers on employment. Course training is the process of students comprehensive apply knowledge to professional practice after a period of theory and practice learning of professional knowledge. It's the process of comprehensive examination of the students' phased learning achievement, and the process of learning and application from the dispersed knowledge to the comprehensive knowledge for students. It is the process of forming comprehensive training on the basis of mastering the relevant course contents. Course training is an important way to improve students' practical skills. All the course teaching is based on practical syllabus and implemented project-based teaching and assessment. Practical teaching is often used in the form of course design, which is an important teaching activities in teaching. How to plan the content of course design, achievement goals and evaluation methods is the key to course design. According to the needs of ability training, we construct the practical teaching system combined with the theory teaching, so as to combine the knowledge transfer and ability cultivation, ability training throughout the whole process of practice teaching.

\section{The Problems in Course Training Teaching}

Course training is an important way to cultivate students' practical consciousness and innovative thinking, improve students' practical ability and ability to analyze and solve practical problems, it is 
an important way to train applied talents. The traditional course training often just let the students be "an armchair strategist", but there is no test of practical application and no physical production, which can not let students fully understand the application value of the course. So it will still lead to disagreement with the production practice and lost the true meaning of course training.

(1) Regular course training is limited to the principle design, which has no principle verification. Students neither debug nor make objects. The assessment is only in the form of written report. Some trainings ask students to write a program for specific design topics and use software to emulate, but after all the software simulation and physical production are different. Therefore they are out of practical application and debugging verification, and ultimately did not achieve the real purpose of the practice.

(2) The implementation process of course training is lack of standardization. Students are not clear about the purpose and stage task of the training so that they are likely to be blind and passive in the training process and can not give full play to their subjective initiative and creativity.

(3)The evaluation method of the course training is simple and lack of the reasonable evaluation standards, so the performance of evaluation is quite arbitrary. If there is no strict and unified evaluation standard in the entire training process, the effectiveness and the intended purpose of the course training will be directly affected.

\section{The Reform Goal of Course Training}

(1) Teachers follow the principles of engineering-oriented, project-driven, ability-cultivated in teaching, to highlight the application, train capacity, guide innovation, and arouse students' interest in engineering practice projects.

(2) Establish the "interactive, heuristic, research-based" teaching mode which emphasize "learning in doing, doing in learning and student-centered mode" under the guidance of teachers to improve the students' autonomous learning ability. Integrate course training with simulation, product (project), process (small system), or system (engineering). Through the integration of the engineering project, a more accurate system framework of the professional knowledge will emerge in front of students, so as to change the phenomenon that students learn not for using but for the exam and forget what they learned after exams. Also, it changes the phenomenon that students learn aimlessly and passively, stimulating students' learning initiative, so that students can learn initiatively and purposefully according to practical engineering project.

(3) Teachers should participate in actively throughout the course training, to help students adjust the time of every stage and guide and supervise the students to complete the design tasks of every stage on time. The assessment of the course training driven by project (engineering) reflect in the concept, design, implementation and operation of the project, focusing on the assessment of the basic skills, comprehensive application ability and innovation ability of students.

(4) By actively exploring the principle of integration of professional education and cultivation of humanistic spirit, we make students have not only a strong practical ability but also a good engineering quality, in order to meet the needs of high-quality applied talents for the construction of innovative countries.

\section{The Project-Based Design of Course Training for the Non-Computer Majors}

Project Alternatives. Taking the MCU course training as an example, we designed and developed a MCU development board for multiple design projects in order to facilitate the course design. The diagram of the structure is shown in Fig. 1 It can be used for the design and development of digital thermometer, digital voltmeter, traffic light control, digital electronic clock, relay control and other basic project design. On the basis of this, it can also be used for the design and development of integrated project, such as the digital clock system with serial timing and alarm functions, the simulation control system of crossroads traffic lights with remote tuning function, and air conditioning analog control system. 


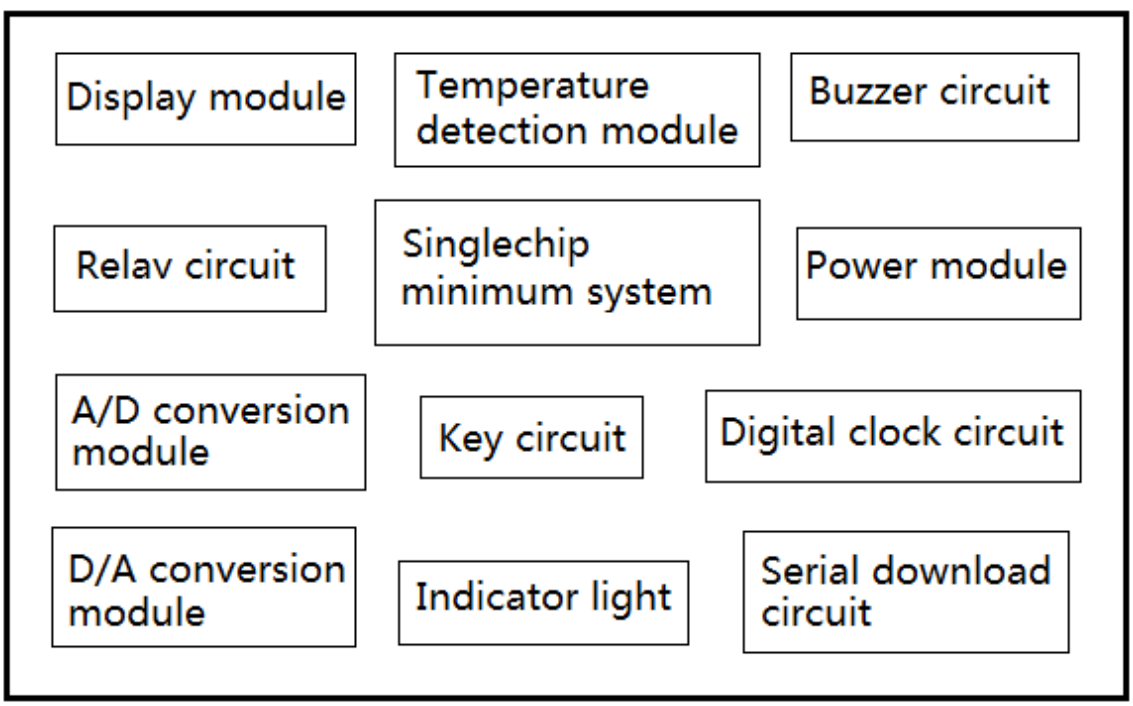

Figure 1. Finite The structure of the development board for MCU course design

According to the specific design issues, students only need to weld the corresponding components in the development board which can achieve the circuit connectivity. Then they need download and debug the appropriate software programs after designing. The product picture of development board is shown in Fig. 2.

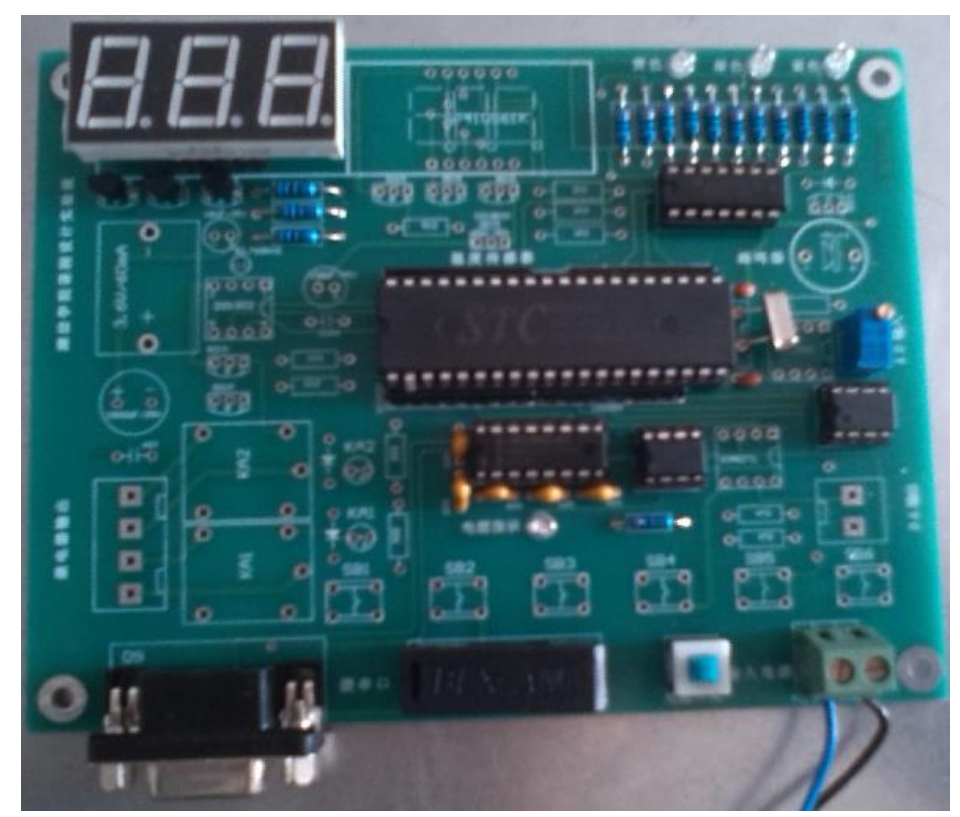

Figure 2. Finite The product picture of the development board in MCU course design

Project Implication. The determination of the design task. Students can independently choose topic according to the MCU development board projects and fill out the course design task book (Fig. 3) Students design realization functions and objectives of the topic they chose, and make arrangements for two weeks' work plan and schedule by themselves. 
MCU Course Design Task Book

\begin{tabular}{|l|l|l|l|l|}
\hline Professional class & & Number & Name & \\
\hline Design topic & & & \\
\hline 1. design tasks and requirements & & \\
2. Schedule & Tutor signature: & \\
\hline Student signature: & Date: & Date: \\
\hline
\end{tabular}

Figure 3. Finite MCU course design task book

The implication of design task. First of all, instructors make requests according to the students' design task book. (1) Use Proteus simulation software to design simulation circuit diagram. (2) Use $\mathrm{C}$ language or assembly language to write software programs in Keil software, and run and complete system simulation in the Proteus. (3) Weld the actual circuit according to the simulation results, and finally burn the process, operate and debug. (4) Summarize the entire design process and write course design report.

In the whole design process, the instructors follow up the design progress all the way and give directions to students to design correctly and effectively in accordance with students' specific design conditions, in order to ensure the smooth completion of course design.

Achievement Evaluation. After the course design, students hand in the simulation software, design object and course design report. The final comprehensive performance is determined by the performance of design report and simulation and the practical manufacture of students' debugging by the teachers in assessment team on scene, and the daily performance given by their own advisors. The performance evaluation table is shown in Fig. 4. 


\section{MCU Course Design Performance Evaluation Form}

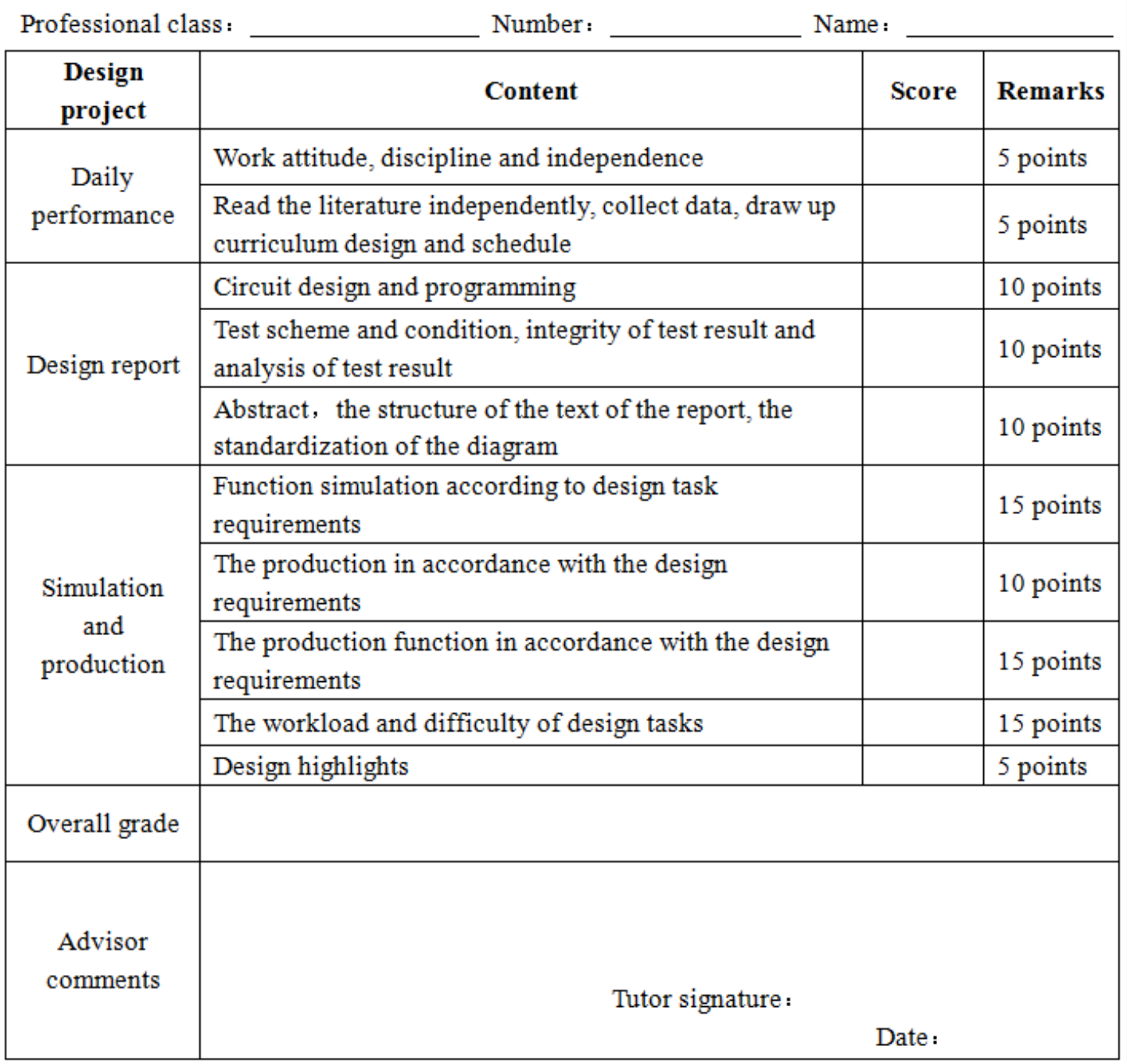

Figure 4. Finite MCU course design performance evaluation form

\section{Conclusion}

Since the implementation of the project-based design method, the MCU course design of the non-computer majors in our collage has achieved remarkable effects.

(1) Students greatly improve the manipulative ability and practical application ability through the course design. Students generally reflect that they are no more blind about and do not know how to use what they learned. At the same time, in the process of practice, students not only find their own interests and strong points but also significantly enhance their employment confidence of the major.

(2) Course design stimulated the design ability and innovation of students, and prompted enthusiasm of students to participate in electronic design contest. The group cooperation in course design helped students know about their specialty. So the reasonable distribution and combination of students with different specialty can help students achieved remarkable results.

(3) The teachers' professional standards have been exercised through their participation and instructions in the entire design process, which avoids the situation that some teachers can only teach but can't make practical projects. Accordingly, teachers can form their own set of the complete and systematic MCU teaching model.

\section{References}

[1] X.L. Xue, Z.Q. Liu and J.R. Jia. The Detailed Explanation of Examples of the Application and 
Development of MCU Interface Module[M].Beijing: Beijing University of Aeronautics and Astronautics Press, 2010.(In Chinese)

[2] C.D. Chen and J. Han. The Principles and Applications of MCU- Experimental Training and Course Design[M].Wuhan: Huazhong University of Science and Technology Press, 2014.(In Chinese)

[3] Q.F. Hu and K.L. Cheng. The Introduction of American Project Research Model[J] . Studies In Foreign Education, 2003(8): 18-21. (In Chinese)

[4] L.Z. Zhang and Y. Zheng. The Application and Discussion of Project - based Teaching Method in the Teaching Reform of Microcomputer Course $[\mathrm{J}]$. China Electric Power Education, 2014(27): 55-58. (In Chinese) 